Waiting time for a haematology consultation in Poland ranges from a couple to several dozen weeks. This is due to the shortage of haematology specialists, their uneven distribution and lack of clear rules regarding patient referrals to outpatient haematology clinics (OHCs). Complete blood count (CBC) is a cheap and widely performed laboratory test. However, in view of problems frequently encountered by primary care physicians with proper interpretation of $\mathrm{CBC}$ results, particularly with the differential diagnosis of malignant blood diseases from benign or reactive abnormalities, we hypothesized that the main reason for referring patients to OHCs might be any $C B C$ deviation. To test this hypothesis, we analysed the structure of patient referrals to the $\mathrm{OHC}$ in Elbląg. Additionally, we sought to establish guidelines for primary care physicians to follow while referring patients identified with $C B C$ abnormalities for haematology assessment.

The study analyses the reasons for 986 patient referrals to the $\mathrm{OHC}$ in Elblag (in 2005-2009). Referrals due to CBC abnormalities were also evaluated to determine their severity. Most of the patients (690) referred to the $\mathrm{OHC}$ were female (70\%). The most common reason for $\mathrm{OHC}$ referral, identified in $33 \%$ of patients with $\mathrm{CBC}$ abnormalities, was anaemia, followed by thrombocytopenia (25\%) and leucopenia (16\%). The severity of CBC abnormalities was mild in the majority of patients. At the time of their first OHC visit, only $60 \%$ of anaemia and thrombocytopenia cases in fact met the criteria for the respective diagnosis, which indicates that the abnormalities resolved spontaneously and could have been monitored by the primary care physician.

Based on the above results and own experience, the authors have proposed practical guidelines on referral indications in the case of CBC abnormalities. The guidelines, coupled with the expansion of knowledge of haematological diseases among primary care physicians, might contribute to reducing the number of patients referred for haematology assessment.

Key words: outpatient haematology clinic, primary care physician, haematologist.

\section{Analysis of patient referrals to the outpatient haematology clinic in Elbląg}

\author{
Jan Zaucha ${ }^{1}$, Krzysztof Adamowicz'2, Marta Zalewska ${ }^{3}$, \\ Aleksandra Zabłocka ${ }^{4}$, Joanna Adamowicz ${ }^{5}$, Andrzej Mital ${ }^{6}$
}

${ }^{1}$ Department of Propedeutic Oncology, Faculty of Health Sciences, Medical University of Gdańsk, Poland

2Regional Oncology Center, Gdansk, Poland

${ }^{3}$ Department of the Prevention of Environmental Hazards and Allergology Faculty of Health Sciences, Medical University of Warsaw, Poland

${ }^{4}$ Graduate of the Faculty of Public Health, Medical University of Gdańsk, Poland ${ }^{5} \mathrm{GP}$ Clinic "Kaszuby", Wejherowo, Poland

${ }^{6}$ Department of Haematology and Transplantology, Medical University of Gdańsk, Poland

\section{Introduction}

Polish patients require referral from their primary care physician in order to make appointments with the majority of medical specialists, haematologists included. Waiting times typically range from a couple to several dozen weeks. In mid June 2010, first-time patients requesting appointment at either of two outpatient haematology clinics (OHCs) operating in Gdańsk had their appointments scheduled for the end of 2011.

Difficulties with obtaining haematology consultations can be attributed to several factors. The most important of them was the number of actively practising haematology specialists, which is indirectly linked to the number of haematology centres operating within a particular area. According to the Central Register of Physicians kept by the Supreme Medical Chamber (NIL) in Warsaw, there are a total of 289 haematology specialists in Poland (275 of whom practise actively). Taking into account the fact that Poland's population exceeds 38 million [1], there is only 0.7 haematologist per 100,000 people in Poland (i.e. one haematologist per 138,000 people). Furthermore, the distribution of haematologists and haematology treatment centres in Poland is uneven. Warsaw, for example, has four large haematology treatment centres including the prominent Haematology Institute. For contrast, the Warmińsko-Mazurskie Province has only one 14-bed haematology inpatient unit with the basic referral level. A report commissioned by the Ministry of Health and prepared by the National Institute of Hygiene points to a large and recently growing diversity in saturation with "haematology beds" between Polish provinces. What is more, the underlying causes of the diversity have been becoming more and more permanent in the last few years. Warmińsko-Mazurskie is the province with the lowest number of haematology beds per 10,000 inhabitants - ca. $66 \%$ fewer than the Polish average [2]. The Pomorskie Province also has just one haematology hospital unit which, however, is the only haematology treatment centre in northern Poland with the 3 rd referral level, i.e. authorized to perform allogeneic transplants from related and unrelated donors. There are 15 registered haematology specialists in the Pomorskie Province and only 3 in the Warmińsko-Mazurskie Province [3]. In 2010, the Pomorskie Province had 2,235,511 inhabitants, while the Warmińsko-Mazurskie Province had 1,427,587 [1], which gives 0.68 and 0.21 haematologist for 100,000 inhabitants in those provinces, respectively. There are no commonly recognized physician-topatient ratios, either in Poland or in Europe, specifying the number of haematologists required for covering health needs of the population. According to 
US estimates for the state of Pennsylvania, the optimum number of professionally active, fully qualified and independently practising haematologists is ca. 1-2 per 100,000 inhabitants [4]. The data suggest that the two Polish provinces listed above do not have enough haematologists, which partially explains the long waiting times for haematology assessment.

Another important cause of difficulties with access to haematology consultations, at least in Poland, is the fact that there are no established guidelines regulating the referral of patients for haematology assessment by primary care physicians, even though CBC is a rather commonly ordered laboratory test. CBC is a part of the basic set of tests performed during periodic health check-ups and should, preferably, be performed in adults at least once a year. Interpretation of CBC results, however, may be problematic, especially if reactive abnormalities are to be differentiated from serious haematopoietic conditions. As a result, patients with any CBC abnormalities may be referred for haematology consultation without any prior attempt to assess dynamics of the abnormalities and their severity, or explain commonly encountered disorders such as anaemia due to iron deficiency. The situation potentially extends waiting times for haematology assessment, making it more difficult for patients requiring urgent treatment to make an appointment with a haematologist.

To verify the hypothesis that the main reason for patient referrals to OHCs is CBC abnormalities, an attempt was made to analyse referrals to the $\mathrm{OHC}$ in Elbląg. Results obtained in the analysis were used as a foundation for guidelines that might be applied to govern patient referrals for haematology consultations in the case of CBC abnormalities.

\section{Material and methods}

The outpatient haematology clinic $(\mathrm{OHC})$ in Elbląg operates within the "Outpatient Oncology Clinic" Non-Public Healthcare Centre (NZOZ) and has a contract with the National Health Fund (NFZ) for the provision of haematology consultations. It is open one day a week and patients are seen by two experienced haematologists from the Pomorskie Province. The span of its operation covers Elbląg city and district, as well as the closest districts of the WarmińskoMazurskie and Pomorskie Provinces: Bartoszycki, Braniewski, Iławski, Kwidzyński, Lidzbarski, Malborski, Nowodworski, Nowomiejski, Ostródzki, Sztumski and Tczewski. Overall, the region is inhabited by ca. 550,000 people [1].

The study was based on a retrospective analysis of the following documents: written referrals to $\mathrm{OHC}$ issued by primary care physicians and medical records documenting patients' follow-up and treatment, whenever any was required. The study covered the period between 14 December 2009 and 16 January 2010. Medical records of a total of 1859 patients receiving treatment at the $\mathrm{OHC}$ were reviewed. A total of 986 patients, whose last OHC visit took place after 2007, were selected for further analysis. Patients who last visited the $\mathrm{OHC}$ in 2006 and before that year were excluded from the study, similarly to patients who had only one appointment at the $\mathrm{OHC}$.

Before undertaking the analysis, a database was created with the following columns: initials, date of birth, gender, place of residence (town/city, district), distance between the place of residence and Elbląg, date of the first appointment, reason for referral, anaemia subtype, if the condition was present (microcytic, macrocytic, normocytic), basic blood parameters (WBC, HGB, PLT), final ICD-10 diagnosis, date of the last recorded appointment, number of followup years, number of appointments per year.

Reasons for $\mathrm{OHC}$ referrals issued by primary care physicians were divided into three main groups: abnormalities in peripheral blood parameters, coagulation disorders and diagnosed proliferative disease. Patients who could not be included in any of the groups listed above were classified as "Other". The group of patients with CBC abnormalities included several subgroups, depending on the abnormality type: leucopenia, leukocytosis, anaemia, polycythemia, thrombocytopenia and thrombocytosis, and duo- or pancytopenia. The following definitions were adopted for the study: leucopenia - WBC $<4 \times 10^{9} /$, leukocytosis - WBC $>10 \times 10^{9} /$, anaemia - HGB $<11.5 \mathrm{~g} / \mathrm{dl}$, polycythemia $-\mathrm{HGB}>16 \mathrm{~g} / \mathrm{dl}$, thrombocytopenia - PLT <100 $\times 109 /$, thrombocytosis - PLT $>400 \times 10^{9} /$. Criteria adopted for thrombocytopenia and anaemia in the study were lower than reference values, based on the authors' clinical experience. Anaemia was classified in accordance with commonly recognized criteria. HGB range for mild anaemia was 10-11.5 g/dl; for moderate anaemia, 8-10 g/dl; for severe anaemia, 6.5-8 g/dl; and for life-threatening anaemia, below $6.5 \mathrm{~g} / \mathrm{dl}$. A similar procedure was followed for the severity of thrombocytopenia and leucopenia. Accordingly, moderate thrombocytopenia was defined as PLT level 50-100 G/l, severe thrombocytopenia 20-49 G/l, and life-threatening thrombocytopenia below $20 \mathrm{G} / \mathrm{l}$. Mild leucopenia was defined as the WBC level > $3 \mathrm{G} / \mathrm{l}$ to < $4 \mathrm{G} / \mathrm{l}$; moderate leucopenia WBC > $2 \mathrm{G} / \mathrm{l}$ to $\leq 3 \mathrm{G} / \mathrm{l}$; and severe leucopenia $W B C \leq 2 \mathrm{G} / \mathrm{I}[5]$.

The study was approved in writing by the NZOZ Manager. A prerequisite for the approval was preparation of a database ensuring full anonymity of the study group. Statistical calculations were performed using Microsoft Excel (ver. 2003) and the R program (ver. 2.6.2) from the R Foundation for Statistical Computing [6].

\section{Results}

\section{Patient demographics}

The vast majority of the 986-patient study group were women (689, i.e. $70 \%)$. The median age in the study group was 59 years (17-92 years) and it was 7 years higher in male patients. The number of patients in each of the age groups is listed in Table 1. The preponderance of women was more pronounced in younger age groups. A statistically significant difference in the proportion of women and men was identified in the younger age group (16-39 years) in relation to the group of patients aged above 60 years $(p=0.0004)$. A similar difference was noted between the group aged between 40 and 60 years, and the group of patients older than 60 years of age $(p=0.0001)$.

\section{Distribution of patients' places of residence}

The vast majority of patients (88\%) lived in towns/cities, of whom $61.2 \%$ lived in Elbląg and the rest in other towns in the vicinity of Elbląg (26.8\%). Only $12 \%$ of patients lived 
Table 1. Age distribution of patients referred to the outpatient haematology clinic in Elbląg

\begin{tabular}{lccccccc} 
Sex & Number & Median age & Range & Age 17-39 (\%) & Age 40-60 (\%) & Age > 60 (\%) \\
\hline Men & 297 & 62 & $17-88$ & 38 & 99 & 160 \\
Women & 689 & 55 & $18-92$ & 131 & 298 & 260
\end{tabular}

Table 2. Residence of patients referred to the outpatient haematology clinic in Elbląg

\begin{tabular}{|c|c|c|c|}
\hline $\begin{array}{l}\text { District* } \\
\text { (according to } \\
\text { database codes) }\end{array}$ & $\begin{array}{l}\text { Number of patients } \\
\text { referred to the clinic }\end{array}$ & $\begin{array}{c}\text { Number of patients } \\
\text { living in rural areas (\%) }\end{array}$ & $\begin{array}{l}\text { Number of patients } \\
\text { living in } \\
\text { towns/cities (\%) }\end{array}$ \\
\hline 1 - Elbląg & 602 & $0(0)$ & $602(100)$ \\
\hline 2 - elbląski & 110 & $52(47)$ & $58(53)$ \\
\hline 3-braniewski & 66 & $10(15)$ & $56(85)$ \\
\hline 5 - iławski & 24 & $0(0)$ & $24(100)$ \\
\hline 8 - sztumski & 30 & $10(33)$ & $20(67)$ \\
\hline 9 - kwidzyński & 18 & $5(28)$ & $13(72)$ \\
\hline 10 - nowodworski & 45 & $17(38)$ & $28(62)$ \\
\hline 11 - malborski & 44 & $9(20)$ & $35(80)$ \\
\hline
\end{tabular}

*only districts with more than 15 referrals are included

Table 3. Reasons for referrals to the outpatient haematology clinic in Elbląg

\begin{tabular}{|c|c|c|c|c|c|}
\hline Disorder type & $\begin{array}{c}\text { Number } \\
\text { of patients (\%) }\end{array}$ & $\begin{array}{c}\text { Number } \\
\text { of women (\%) }\end{array}$ & $\begin{array}{c}\text { Median age } \\
\text { of women (years) }\end{array}$ & $\begin{array}{c}\text { Number } \\
\text { of men (\%) }\end{array}$ & $\begin{array}{l}\text { Median age } \\
\text { of men (years) }\end{array}$ \\
\hline $\begin{array}{l}\text { Abnormalities in results } \\
\text { of } C B C \text { or other laboratory } \\
\text { tests }\end{array}$ & $777(78.8)$ & $563(72.5)$ & 54 & $214(27.5)$ & 61 \\
\hline $\begin{array}{l}\text { Coagulation system } \\
\text { disorders* }\end{array}$ & $49(5.0)$ & $36(73.5)$ & 46 & $13(26.5)$ & 46 \\
\hline Proliferative diseases & $160(16.2)$ & $90(56.2)$ & 67.5 & $70(43.8)$ & 67 \\
\hline Total & $986(100)$ & 689 & & 297 & \\
\hline
\end{tabular}

*the broad group of coagulation disorders comprised both patients with suspected bleeding diathesis (21 people) and thrombophilia (29 people)

in rural areas. Most towns and villages whose residents travelled to the outpatient haematology clinic in Elbląg are located within a $100 \mathrm{~km}$ radius from Elbląg. The majority (72\%) of patients were referred from Elbląg itself and from the Elbląg district. Another $22 \%$ of patients lived in directly neighbouring districts. The remaining patients lived at a greater distance.

Analysing towns/cities besides Elbląg, the highest proportion of patients were originally from Braniewo (44 patients; 44 km away from Elbląg), followed by Pastęk (41 patients; $22.4 \mathrm{~km}$ away from Elbląg), Malbork (27 patients; $32 \mathrm{~km}$ away from Elbląg) and Nowy Dwór Gdański (26 patients; 24.3 km away from Elblag). Detailed data regarding places of residence of patients referred to the outpatient haematology clinic are listed in Table 2.

Data included in referrals by the referring physician

$\mathrm{OHC}$ referrals issued by the primary care physician, divided into four main groups (CBC abnormalities, coagulation dis- orders, diagnosed proliferative disease and others) are listed in Table 3. The dominant group comprised CBC abnormalities (79\%). Out of this group, the most common reason for referrals (33\%) was anaemia, followed by thrombocytopenia (23\%) and leucopenia (16\%). Other reasons (leukocytosis, polycythemia and thrombocytosis) did not account for $10 \%$ of all referrals. Nearly all the groups were dominated by women, particularly the group of referrals issued due to anaemia and leucopenia (the women-to-men ratio was almost 5:1 - cf. Table 4). Referrals issued to 30 patients were classified as "Other", including lymphadenopathy (6), suspected haemosiderosis and high serum iron level (4), macrocytosis without anaemia (2), history of acute leukaemia (3), hypogammaglobulinaemia (1), cryoglobulinaemia (1), epigastric tumour (1), HCV-related hepatosplenomegaly (1), weakness or malaise (2), Raynaud's phenomenon (2), increased reticulocyte count (1), elevated IgA level (1), Castleman's disease (1), sibling leukaemia (1), subconjunctival haemorrhage (1), PLT aggregates visible in the blood smear or blood smear abnormalities (2). 
Table 4. The most common reasons for referrals in the group with CBC abnormalities

\begin{tabular}{|c|c|c|c|c|c|c|c|c|}
\hline \multirow[t]{2}{*}{ Disorder type } & \multirow[t]{2}{*}{ Number } & \multirow[t]{2}{*}{$\%$} & \multirow[t]{2}{*}{$\begin{array}{c}\text { Age } \\
\text { (mean) }\end{array}$} & \multicolumn{2}{|c|}{$\begin{array}{c}\text { Sex } \\
\%\end{array}$} & \multicolumn{2}{|c|}{$\begin{array}{l}\text { Age } \\
\text { (mean) }\end{array}$} & \multirow[t]{2}{*}{$\begin{array}{l}\text { Women-to } \\
\text {-men ratio }\end{array}$} \\
\hline & & & & $\mathrm{F}$ & $M$ & $\mathrm{~F}$ & M & \\
\hline Leucopenia & 114 & 15.3 & $50.5 \pm 14.43$ & 84 & 16 & 50 & 60.6 & 5.25 \\
\hline Leukocytosis & 47 & 6.3 & $61.3 \pm 12.13$ & 47 & 53 & 61 & 61.6 & 0.89 \\
\hline Thrombocytopenia & 169 & 22.7 & $56.2 \pm 17.75$ & 62 & 38 & 53.9 & 60 & 1.63 \\
\hline Thrombocytosis & 70 & 9.4 & $63.0 \pm 14.14$ & 70 & 30 & 62.9 & 63.4 & 2.33 \\
\hline Anaemia & 248 & 33.2 & $53.9 \pm 17.10$ & 82 & 18 & 52.5 & 60.6 & 4.55 \\
\hline Polycythemia & 48 & 6.4 & $67.1 \pm 12.27$ & 52 & 48 & 71.9 & 61.8 & 1.08 \\
\hline \multicolumn{9}{|l|}{ Bicytopenias } \\
\hline and pancytopenias & 50 & 6.7 & $59.0 \pm 16.13$ & 78 & 22 & 57.2 & 65.3 & 3.54 \\
\hline Total & 746 & & & & & & & \\
\hline
\end{tabular}

Table 5. Number of patients referred due to CBC abnormalities meeting generally accepted criteria for clinically significant leucopenia, leukocytosis, anaemia, thrombocytopenia and thrombocytosis

\begin{tabular}{lcccc|}
$\begin{array}{l}\text { Disorder } \\
\text { type }\end{array}$ & Number & Definition & Number & Percentage \\
\hline Leucopenia & 114 & WBC $<4 \mathrm{G} / /$ & 94 & 82 \\
\hline Leukocytosis & 47 & $\mathrm{WBC}>10 \mathrm{G} / \mathrm{l}$ & 41 & 87 \\
\hline $\begin{array}{l}\text { Thrombocy- } \\
\text { topenia }\end{array}$ & 169 & $\mathrm{PLT}<100 \mathrm{G} / \mathrm{l}$ & 98 & 58 \\
\hline $\begin{array}{l}\text { Thrombocytosis } \\
70\end{array}$ & $\mathrm{PLT}>400 \mathrm{G} / \mathrm{l}$ & 65 & 93 \\
\hline Anaemia & 248 & $\mathrm{HGB}<11.5 \mathrm{~g} / \mathrm{dl}$ & 141 & 57 \\
\hline Polycythemia & 48 & $\mathrm{HGB}>16.0 \mathrm{~g} / \mathrm{dl}$ & 38 & 79 \\
\hline
\end{tabular}

Table 6. Severity of anaemia in 248 patients referred because of anaemia

\begin{tabular}{lccc}
$\begin{array}{l}\text { Severity of } \\
\text { anaemia }\end{array}$ & $\begin{array}{l}\text { Haemoglobin } \\
\text { concentration }\end{array}$ & $\begin{array}{c}\text { Number of } \\
\text { patients }\end{array}$ & (\%) \\
\hline Mild & $>10$ to $\leq 11.5 \mathrm{~g} / \mathrm{dl}$ & 131 & 53 \\
Moderate & $>8$ to $\leq 10 \mathrm{~g} / \mathrm{dl}$ & 78 & 31 \\
\hline Severe & $>6.5$ to $\leq 8 \mathrm{~g} / \mathrm{dl}$ & 20 & 8 \\
\hline Life-threatening & $\leq 6.5 \mathrm{~g} / \mathrm{dl}$ & 11 & 4 \\
\hline No anaemia & other & 8 & 3
\end{tabular}

Additionally, it was determined how many patients with referrals specifying CBC abnormalities in fact met the criteria defined in the study for leucopenia, leukocytosis, anaemia, polycythemia, thrombocytopenia and thrombocytosis at the time of their first CBC test performed at the outpatient haematology clinic. Results are listed in Table 5 below. In nearly all subgroups, with the exception of referrals due to anaemia and thrombocytopenia, $\mathrm{CBC}$ results in the majority of patients ( $\geq 80 \%$ ) met the numerical criteria of the condition specified as the reason for their $\mathrm{OHC}$ referral. In groups referred due to anaemia or thrombocytopenia, only slightly more than $50 \%$ of patients satisfied the numerical criteria adopted for the study.
Analysis of types and severity of selected CBC disorders specified as reasons for OHC referral

\section{Anaemia}

In the subgroup of 245 patients referred to the outpatient haematology clinic due to anaemia, the most common anaemia type based on red blood cell volume was microcytic anaemia (44.5\%), followed by the normocytic (31.5\%) and macrocytic (24\%) types.

Analysing 109 patients with microcytic anaemia, the majority (83 patients) were found to have iron deficiency. Three patients were diagnosed with von Willebrand disease in addition to iron deficiency anaemia, while two patients had thrombocytosis with no evidence of iron deficiency. Two patients were diagnosed with hypothyroidism, three with microspherocytosis. In 16 patients, anaemia diagnosis was either not confirmed or the underlying cause of anaemia could not be established.

In the group of 77 normocytic anaemia patients the cause of the condition was only determined in 18 patients. Out of that number, 11 patients were diagnosed with anaemia of chronic disorders and 7 were ultimately diagnosed with proliferative diseases (myelodysplastic syndromes in 5, primary myelofibrosis in 1 and myeloma in 1 ).

The subgroup of 59 patients with macrocytic anaemia was dominated by patients with vitamin B12 deficiency (45 individuals). One was diagnosed with folic acid deficiency, two with autoimmune haemolytic anaemia and six with myelodysplastic syndrome. The underlying cause of macrocytosis could not be identified in 5 patients.

The severity of anaemia in 248 patients referred to the outpatient haematology clinic due to anaemia is presented in Table 6. Most patients (84\%) had a mild (53\%) or moderate (31\%) form of anaemia. In $8 \%$ of patients anaemia was severe and in 4\% life-threatening. Two patients had haemoglobin levels lower than $6 \mathrm{~g} / \mathrm{dl}$.

\section{Thrombocytopenia}

Thrombocytopenia was the reason for referral to the outpatient haematology clinic in a total of 169 patients. Out of that group, however, in 42\% (71 patients) the PLT count was 
not $<100 \mathrm{G} /$, of whom 6 patients had a PLT count higher than $150 \mathrm{G} / \mathrm{l}$. Most of the remaining proportion of patients (46\%) were diagnosed with moderate thrombocytopenia. Only 20 patients $(12 \%)$ required urgent diagnostics of thrombocytopenia. Five were diagnosed with life-threatening thrombocytopenia. The majority were ultimately diagnosed with idiopathic thrombocytopenia. Thrombocytopenia was the first symptom of lymphoma and/or chronic lymphocytic leukaemia in 5 patients. Pseudothrombocytopenia was identified in 2 patients. The remaining patients were diagnosed with other conditions: chronic liver disease (chronic viral hepatitis, toxic liver damage or autoimmune hepatitis) in 4 patients. Data are listed in Table 7 below.

\section{Leucopenia}

Leucopenia was the reason for $\mathrm{OHC}$ referral in 114 patients. $\mathrm{CBC}$ results presented by patients at their first appointment showed no leucopenia in 20 cases. The majority of referred patients had mild leucopenia and $25 \%$ had moderate leucopenia. Only 2 patients fulfilled the criteria of severe leucopenia (Table 8 ). In only 3 patients (2.5\%), leucopenia was the first symptom of a haematopoietic proliferative disorder (myelodysplastic syndrome).

\section{Analysis of proliferative diseases requiring referral} to outpatient haematology clinic

Types of haematopoietic proliferative disorders resulting in referral for specialist haematology care are listed in Table 9. The referrals were dominated by lymphoma diagnoses (80\%). Myeloproliferative neoplasms were mentioned in $20 \%$ of referrals, the most common being myelodysplastic syndromes. The group of patients with referrals issued due to myeloproliferative neoplasms excluded cases of thrombocytosis and polycythemia, which were included in the group of referrals due to CBC abnormalities.

\section{Diagnosis of proliferative disease during diagnostic procedures performed in the clinic}

Table 10 shows results of analysis carried out to determine how many patients were diagnosed with a haematopoietic proliferative disorder during their treatment at the haematology clinic. Lymphomas were the most common disorders (33 patients), especially chronic lymphocytic leukaemia (CLL). Myelodysplastic syndromes were less prevalent (31 cases), similarly to myeloproliferative neoplasms (16 cases), mainly myelofibrosis. Hodgkin lymphoma diagnosis was also verified in 2 patients (one was ultimately confirmed to have toxoplasmosis and the other chronic lymphocytic leukaemia).

\section{Frequency of appointments at the outpatient haematology clinic}

The median number of appointments at the outpatient haematology clinic for all patients who were analysed and followed up for longer than 12 months was 4.5 appointments per year, which gives a median frequency of 2.6 months. Follow-up was the least frequent in leucopenia and thrombocytopenia patients: once every 3.4 and 3.1 months, respectively. Patients suffering from proliferative diseases, either of the lymphatic system or bone marrow, were followed up more
Table 7. Severity of thrombocytopenia in 169 patients referred because of thrombocytopenia

\begin{tabular}{lccc|}
\hline $\begin{array}{l}\text { Severity } \\
\text { of thrombocytopenia }\end{array}$ & PLT count & $\begin{array}{c}\text { Number } \\
\text { of patients }\end{array}$ & $\%$ \\
\hline Moderate & $>50 \mathrm{G} / \mathrm{l}$ to $\leq 100 \mathrm{G} / \mathrm{l}$ & 78 & 46 \\
\hline Severe & $<20 \mathrm{G} / \mathrm{l}$ to $\leq 50 \mathrm{G} / \mathrm{l}$ & 15 & 9 \\
\hline Life-threatening & $>100 \mathrm{G} / \mathrm{l}$ & 5 & 3 \\
\hline No thrombocytopenia & $>100 \mathrm{G} / \mathrm{l}$ and $\leq 150 \mathrm{G} / \mathrm{l}$ & & 42 \\
\hline *including 65 patients with $P L T>11^{*}$ &
\end{tabular}

Table 8. Severity of leucopenia in 114 patients referred because of leucopenia

\begin{tabular}{lccc}
\hline Severity of leucopenia & WBC count & $\begin{array}{c}\text { Number } \\
\text { of patients }\end{array}$ & $\%$ \\
\hline Mild & $>3 \mathrm{G} / \mathrm{l}$ to $4 \mathrm{G} / \mathrm{l}$ & 65 & 57 \\
\hline Moderate & $>2 \mathrm{G} / \mathrm{l}$ to $\leq 3 \mathrm{G} / \mathrm{l}$ & 27 & 24 \\
\hline Severe & $<2 \mathrm{G} / \mathrm{l}$ & 2 & 2 \\
\hline No leucopenia & 20 & 18 \\
\hline Total & 114 & 100
\end{tabular}

Table 9. Characteristics of haematopoietic proliferative disorders in patients referred due to diagnosed proliferative disease

\begin{tabular}{|lcc|}
\hline Disease & $\begin{array}{c}\text { Number } \\
\text { of patients }\end{array}$ & $\%$ \\
\hline Chronic myeloid leukaemia & 3 & 1.1 \\
\hline Myelofibrosis & 5 & 1.8 \\
\hline Myelodysplastic syndromes & 24 & 8.9 \\
\hline Multiple myeloma & 15 & 5.5 \\
\hline Hodgkin's lymphoma & 12 & 4.4 \\
\hline Non-Hodgkin's lymphoma & 106 & 39.1 \\
\hline Chronic lymphocytic leukaemia & 73 & 26.9 \\
\hline Hairy cell leukaemia & 1 & 0.4 \\
\hline Large B-cell lymphoma & 10 & 3.7 \\
\hline Mantle cell lymphoma & 5 & 1.8 \\
\hline Follicular lymphoma & 2 & 0.7 \\
\hline T-cell lymphoma & 3 & 1.1 \\
\hline Other non-Hodgkin's lymphomas & 271 & 100 \\
\hline Total & 3.4 \\
\hline
\end{tabular}

frequently (once every 2.5 months). The highest follow-up frequency (every 2.2 months) was in patients with coagulation disorders (thrombophilia and haemorrhagic diathesis).

\section{Discussion}

Diseases of the haematopoietic system have a relatively low incidence, morbidity and mortality compared to circulatory diseases or cancers of parenchymal origin [5]. Haematopoietic diseases include both cancerous and non- 
Table 10. Diagnosis of haematological malignancies made under the care of the outpatient haematology clinic in Elbląg

\begin{tabular}{|c|c|c|c|}
\hline Disease & $\begin{array}{l}\text { Number of cases on } \\
\text { the basis of diagnosis } \\
\text { specified in referral }\end{array}$ & $\begin{array}{l}\text { Number of cases on } \\
\text { the basis of records from } \\
\text { the last haematology appointment }\end{array}$ & Change \\
\hline Chronic myeloid leukaemia & 3 & 3 & 0 \\
\hline Myelofibrosis & 5 & 21 & 16 \\
\hline Myelodysplastic syndromes & 24 & 55 & 31 \\
\hline Multiple myeloma & 15 & 15 & 0 \\
\hline Hodgkin's lymphoma & 12 & 10 & -2 \\
\hline Non-Hodgkin's lymphoma & 106 & 139 & 33 \\
\hline
\end{tabular}

Table 11. Proposed criteria of cell blood count changes constituting reasons for patient referral to outpatient haematology clinic

\begin{tabular}{lll}
\hline CBC parameter & Value & Note \\
\hline WBC & $<4 \mathrm{G} / \mathrm{confirmed}$ in at least two tests performed at 3-month intervals \\
\hline Neutrocyte count & $<1.5 \mathrm{G} / \mathrm{l}$ & confirmed in at least two tests performed at 3-month intervals \\
\hline Haemoglobin & $<11.5 \mathrm{~g} / \mathrm{dl}$ & $\begin{array}{l}\text { If iron deficiency is excluded or, if it is confirmed, its underlying causes cannot be } \\
\text { established; or in the case of poor tolerance of oral iron therapy }\end{array}$ \\
\hline PLT count & $<100 \mathrm{G} / \mathrm{If}$ pseudothrombocytopenia and liver diseases are excluded \\
\hline Peripheral blood smear & Blastic cells & $\begin{array}{l}\text { Urgent consultation is required if blastic cells identified in peripheral blood smear. } \\
\text { Peripheral blood smear should be ordered if any abnormalities in CBC parameters } \\
\text { are noted. }\end{array}$
\end{tabular}

cancerous conditions. They require haematology specialists to possess an in-depth knowledge of differential, cytological, cytogenetic and molecular diagnostics. Irregularities identified during physical examination or in laboratory tests are rarely specific to particular diseases. This is especially true for changes identified in CBC results. Similar abnormalities can also occur in other diseases, many of which are of nonhaematological origin. Differentiation between CBC abnormalities which potentially suggest a serious disease and reactive changes, or normal physiological variations, is by no means easy. The medical practitioner must have a thorough knowledge of patient management if specific irregularities are revealed. Based on the experience of haematologists, and the authors' own practice, primary care physicians rarely make any attempt to classify their patients' peripheral blood findings and quickly refer them for specialist haematology consultations. This tendency underlies the authors' hypothesis, expounded here, that the main reason for patient referrals to outpatient haematology clinics is abnormalities identified in CBC parameters, not diagnosed diseases. The situation is thus opposite to e.g. outpatient oncology clinics, which rarely receive patients reporting only irregularities confirmed in additional tests. This course of action substantially increases the number of patients referred for haematology consultation, which extends the waiting time for the first appointment and makes it more difficult for patients suffering from serious haematological conditions demanding quick interventions to receive proper medical care.

Results of studies fully corroborate the above hypothesis. The vast majority (nearly $80 \%$ ) of referrals to outpatient haematology clinics concerned patients with changes in peripheral blood parameters identified during periodic health screening or hospitalization for other reasons. Diagnosed haematological proliferative disorders were a reason for only approx. $20 \%$ of patient referrals. It is also interesting to note that the majority of referred patients (70\%) were women, which contradicts epidemiological data for most proliferative diseases of the haematopoietic system, which demonstrate a slightly higher incidence in men than women [5, 7]. Differences in median age between women and men, as well as variation in women-to-men ratio in different age groups, show explicitly that young women (< 40 yrs. old) are much more frequently referred for haematology assessment than young men. The age difference is largely accounted for by referrals due to CBC irregularities, particularly anaemia and thrombocytopenia, and less frequently leucopenia.

The considerable predominance of women in referrals due to anaemia can be explained by physiological factors and by the fact that women are more often diagnosed with autoimmune diseases such as inflammatory diseases of joints and connective tissues [8]. The main reason for referrals (nearly a half of all patients) was microcytic anaemia most commonly triggered by iron deficiency. The main cause of macrocytic anaemia was, in turn, vitamin B12 deficiency. Both observations conform to epidemiological evidence [5]. It needs to be noted, though, that macrocytic anaemia can be an isolated symptom of myelodysplastic syndrome (particularly among elderly patients), cirrhosis, alcoholism or hypothyreosis [5]. The greatest challenge is establishing the underlying cause of normocytic anaemia. In the analysed material, the cause could only be determined in $23 \%$ of patients referred due to normocytic anaemia. The most common causes included anaemia of chronic disorders and proliferative diseases. It is also worth mentioning that assum- 
ing the definition of anaemia adopted for the study ( $\mathrm{Hgb}$ $<11.5 \mathrm{~g} / \mathrm{dl}$ ), which proves useful in daily clinical practice, $43 \%$ of patients referred due to anaemia in fact failed to satisfy the definition's parameters. Patients from this group (with $\mathrm{Hgb}>11.5 \mathrm{~g} / \mathrm{dl}$, though below laboratory reference ranges) can be monitored by primary care physicians. None of those patients were diagnosed with any haematopoietic proliferative disorders. The anaemia criterion adopted for the study can, therefore, be proposed as the decisive factor determining patient referral to the outpatient haematology clinic after excluding the most frequent cause of anaemia, i.e. iron deficiency - or vitamin B12 deficiency for macrocytic anaemias (cf. Table 11) [5, 9].

The second most common reason for referrals for haematological assessment was thrombocytopenia. Identifying the cause of thrombocytopenia is a difficult task and calls for multiple additional tests. Spontaneous thrombocytopenia is diagnosed by ruling out other potential causes [7]. Because of practical considerations, the study defines thrombocytopenia as a platelet $(P L T)$ count $<100 \mathrm{G} / \mathrm{l}$. The definition was adopted because patients with PLT < $150 \mathrm{G} / \mathrm{l}$, but > $100 \mathrm{G} / \mathrm{l}$ only require monitoring, without any treatment. In the study material, they accounted for $38 \%$ of patients. The majority of others were diagnosed with moderate thrombocytopenia (PLT > $50 \mathrm{G} / \mathrm{l}$ ). If the platelet count did not change and no other CBC irregularities were detected, the patients were only monitored, without any treatment being necessary. Results presented above lead to the conclusion that patients should be referred to an outpatient haematology clinic if their platelet count falls below $100 \mathrm{G} / \mathrm{l}$, which signifies moderate thrombocytopenia. For the remaining patients, monitoring by a primary care physician is sufficient (cf. Table 11).

The third most common reason for referrals was leucopenia. Similarly to thrombocytopenia, leucopenia was mild to moderate in the majority of patients (83\%). Severe leucopenia was only diagnosed in 2 patients. Another fact worth mentioning is that no leucopenia was confirmed in the first CBC test performed in the outpatient haematology clinic in $17 \%$ of patients initially referred for haematology assessment, which shows that abnormalities identified in these patients were transient or reactive in nature, and they did not need haematology referral in the first place. Follow-up by a primary care physician and repeated CBC testing during the following 3 months would make it possible for a large proportion of patients to avoid reporting for haematology appointment. The safety of the procedure (cf. Table 11) is substantiated by the fact that only a very minor proportion of patients (2.5\%) referred due to leucopenia were later diagnosed with a haematopoietic proliferative disorder.

Diagnosed proliferative diseases represented $16.7 \%$ of referrals to the outpatient haematology clinic. The proliferative to non-proliferative disease ratios in all the districts under analysis ranged from 16 to $32 \%$ (mean: $24 \%$ ). The category of proliferative diseases was dominated by chronic diseases, of which chronic lymphocytic leukaemia was the most common (42\%), followed by myelodysplastic syndromes (15\%). Considering all the patients suffering from proliferative diseases treated at the outpatient haematology clinic, the morbidity ratio is $31 / 100,000$. Because of simple diagnostic cri- teria (histopathological examination of lymph nodes and cytometric analysis of peripheral blood lymphocytes), the most reliable incidence data concern lymphomas, including chronic lymphocytic leukaemia (CLL). Data reflecting the general incidence rate of lymphomas do not indicate a growing tendency for lymphoma cases in the service area of the outpatient haematology clinic in Elblą. In 2004-2009, the lymphoma incidence rate in the area was ca. 15/100,000 and the CLL incidence rate was ca. 2/100,000 of the population, which is consistent with epidemiological data [7, 10].

Data for chronic myeloproliferative disorders were more difficult to obtain. Patients with suspected chronic myeloid leukaemia were referred to the Outpatient Haematology Clinic in Olsztyn because the Elblacg centre lacked equipment for cytogenetic and molecular diagnostics, and possibilities of treatment with tyrosine kinase inhibitors. Lack of possibilities for performing molecular tests (of mutations in the JAK-2 gene) poses great difficulties for unambiguous diagnosis of polycythemia vera and essential thrombocytosis in daily clinical practice. The reliability of data reflecting the incidence of chronic myeloproliferative neoplasms might be called into question, which is why neither the incidence nor the incidence proportion of these diseases was analysed.

Patients suffering from acute leukaemias also constituted a minor group (just 4 patients). All of them had been in remission for a longer period. Patients with newly diagnosed acute leukaemias were admitted to internal medicine units in Elbląg and then, after assessment, were referred to the Haematology Unit in Olsztyn. Since the outpatient haematology clinic in Elbląg does not have a haematology day care unit, the management of patients with acute leukaemias that are not eligible for intensive chemotherapy was not possible.

The vast majority (88\%) of referred patients had their permanent residence in the city. The percentage share of urban population in the Warminsko-Mazurskie Province is ca. $60 \%$ [1], which could suggest that rural populations have worse access to haematology consultations. This stems either from the fact that rural residents go for medical appointments less frequently or medical practitioners in rural areas refer patients for specialist medical assessments less often than in cities. The most likely explanation for the above findings is, however, the difficulty faced by rural residents living in areas located the farthest from Elbląg, as they were mainly represented by urban residents. In districts situated the shortest distance from the city, Elbląg and Nowy Dwór districts, the proportions of urban and rural populations among patients referred to the outpatient haematology clinic were similar to the general urban-to-rural population ratio in the Warmińsko-Mazurskie Province. This observation suggests that a uniform distribution of haematology treatment centres is an essential factor for ensuring better access to specialist haematology care in Poland.

Patients referred to outpatient haematology clinics need at least several appointments to establish a management plan. Those with moderate CBC abnormalities only require monitoring; hence their frequency of appointments in the clinic is the lowest. Patients suffering from proliferative diseases need treatment, which is why their follow-up visits 
should take place at least once every 2.5 months. High frequency of appointments among patients with coagulation system disorders is a consequence of high prices of laboratory tests: only one highly specialist test can be ordered per appointment so as not to exceed the appointment's point value. Taking into account the frequency of appointments, it can be roughly assumed that the majority of patients served by the outpatient clinic are seen once every 2.5 months. Assuming the maximum number of patients (ca. 25 daily), only 250 patients can be examined during that period. If $160 \mathrm{pa}-$ tients with proliferative diseases report to the clinic, only 90 patients with other diseases can be examined. If the clinic was open 5 days a week, during 2.5 months it would be possible to see 1,250 patients, which would fully cover the needs of the region under analysis.

Estimating the demand for specialist haematology services on the basis of collected data is not an easy task. However, an estimation attempt can be made based on data gathered for the Elblag city and the Elbląg district, from which the greatest number of patients were referred to the outpatient clinic (72\%; 713 patients in total). Transport was not an issue for patients here. There are three hospitals operating within the area, which gives grounds to assume that all patients requiring haematology assessment reported to the outpatient haematology clinic. The area under study is inhabited by approx. 183,000 people. If the assumptions presented above were to be accepted, providing the patients with outpatient care would require 30 days of clinic operation. Consequently, the clinic would have to be open every other day. On that basis, it can be assumed that one haematology specialist is needed for outpatient care per $360,000 \approx 400,000$ inhabitants. The area should also have an inpatient haematology unit (with at least two haematology specialists) and a haematology day care unit with one medical practitioner. Excluding days off work, calculations give the figure of 4 medical practitioners per 400,000 people, i.e. similar to the ratio estimated by US authors.

Summing up, the study presented here is Poland's first attempt at evaluating the structure of patient admissions to the regional outpatient haematology clinic from an area where no other haematology treatment centre operates and there are no private haematology practices. Results of the study show CBC abnormalities to be the most common reason for referrals to the clinic. Some of the referred patients could be followed up for a longer period by their primary care physicians, which would eliminate the practice of referring patients with transient reactive changes. The number of patients waiting for haematology assessment could be further reduced if some of the patients, especially those with anaemia, had iron and vitamin B12 deficiency excluded. Table 11 lists proposed levels of quantitative irregularities in CBC parameters which should be followed in referring patients for haematology assessment. Haematology assessment is urgently needed in patients with severe disorders, blast cells seen on peripheral blood smear, or diagnosed proliferative diseases. Peripheral blood smear should be ordered if any abnormalities in CBC parameters are noted. Patients with life-threatening conditions require quick hospitalization. The demand for haematology services estimated in the study is open to discussion. Unfortunately, and for unclear reasons, there does not seem to be much interest in the topic, even through the existing situation gives rise to differences in access to haematology care in Poland and hinders the development of modern Polish haematology.

In conclusion:

1. The majority of patients are referred to the outpatient haematology clinic in Elbląg because of abnormalities detected in their $\mathrm{CBC}$ results.

2. Most of the patients referred to $\mathrm{OHC}$ were women, especially in the group under 40 years of age.

3. The most common $\mathrm{CBC}$ abnormality resulting in $\mathrm{OHC}$ referrals was anaemia, followed by thrombocytopenia and leucopenia.

4. The severity of CBC abnormalities in the majority of referred patients was mild or moderate.

5. The most common proliferative diseases recorded among $\mathrm{OHC}$ patients were lymphomas, of which chronic lymphocytic leukaemia was the most prevalent.

6. Patients with proliferative diseases and with blood coagulation disorders required the most frequent $\mathrm{OHC}$ visits (every 2.5 months and every 2.2 months, respectively).

\section{References}

1. Nowak L., Stańczyk J., Znajewska A., Ludność. Stan i struktura w przekroju terytorialnym (Stan w dniu 30 VI 20010 r.), Główny Urząd Statystyczny, Warszawa 2010.

2. Indicators for the project of establishment of a hospital network with elements of analyses of demographics and health status of the population. Material prepared for the Minister of Health by the National Institute of Hygiene using databases of the Healthcare Information Systems Centre and the National Institute of Hygiene regarding hospital infrastructure and activity. Warsaw 2006.

3. Information obtained orally from the Register of Physicians kept in the District Chamber of Physicians in Gdańsk and the District Chamber of Physicians in Olsztyn, respectively.

4. Cooper RA. An economic and demographic assessment of the demand for Medical Oncologists and Hematologist-Oncologists to serve the adult population to the year 2020, The Medical Oncology Workforce.

5. Hellmann A. Choroby układu krwiotwórczego. In: Choroby wewnętrzne. Szczeklik A. (ed.). Medycyna Praktyczna, Kraków 2010; 1443-650.

6. R Development Core Team (2008). R: A language and environment for statistical computing. R Foundation for Statistical Computing, Vienna, Austria. ISBN 3-900051-07-0, URL http://www.Rproject.org.

7. Dmoszyńska A, Robak T. Podstawy hematologii. Wydawnictwo Czelej, Lublin 2003

8. Zimmermann-Górska I. Choroby reumatyczne. W: Choroby wewnętrzne. Szczeklik A (ed.). Medycyna Praktyczna, Kraków 2010; 1657-835.

9. Hughes-Jones NC, Wickramasinghe SN. Hematologia. Urban \& Partner, Wrocław 2000.

10. Herold G. Hematologia. In: Medycyna wewnętrzna. Herold G. (ed.) Wydawnictwo Lekarskie PZWL, Warszawa 2005; 19-139.

\section{Address for correspondence \\ Jan Zaucha \\ Department of Propedeutic Oncology \\ Faculty of Health Sciences \\ Medical University of Gdańsk \\ Powstania Styczniowego 9b \\ 81-519 Gdynia}

